\title{
HARDY-HILBERT'S INEQUALITY WITH GENERAL HOMOGENEOUS KERNEL
}

\author{
IVAN PERIĆ AND PREDRAG VUKOVIĆ
}

Abstract. A general form of recently obtained Hardy-Hilbert's inequality with perturbed Hilbert's kernel with the best possible estimation in the case of conjugate exponents is obtained. The multidimensional case is also considered. The case of non-conjugate exponents is briefly given.

Mathematics subject classification (2000): 26D15.

Keywords and phrases: Hardy-Hilbert's inequality, homogeneous kernel, the best possible constant, conjugate exponents, non-conjugate exponents, the hypergeometric function.

\section{REFERENCES}

[1] Y. Bicheng, I. BRnetić, M. KRniĆ, J. PeČARIĆ, Generalization of Hilbert and Hardy-Hilbert integral inequalities, Math. Inequal. Appl. 8(2) (2005), 259-272.

[2] F. F. Bonsall, Inequalities with non-conjugate parameters, Quart. J. Math. Oxford Ser. (2) 2 (1951), $135-150$.

[3] I. BRnetić, M. KRnIĆ, J. PeČARIĆ, Multiple Hilbert's and Hardy-Hilbert's Integral inequality with Non-Conjugate Parameters, Bull. Austral. Math. Soc. 71 (2005), 447-457

[4] G. H. Hardy, J. E. Littlewood, G. Pólya, Inequalities, $2^{\text {nd }}$ edition, Cambridge University Press, Cambridge, 1967.

[5] M. Krnić, G. Mingzhe, J. PeČArić, G. XuemeI, On the best constant in Hilbert's inequality, Math. Inequal. Appl. 8(2) (2005), 317-329

[6] M. KRnIĆ, J. PeČARIĆ, General Hilbert's and Hardy's Inequalities, Math. Inequal. Appl. 8(1) (2005), 29-52

[7] Y. LI, J. Wu, B. HE, A New Hilbert-type Integral Inequality and the equivalent form, Intern. Journ. of Math. and Mathem. Sciences, Vol. 2006, Art. ID 45378, 1-6.

[8] Y. LI, W. ZHIPING, B. HE, Hilbert's type linear operator and some extensions of Hilbert's inequality, (accepted in J. Inequal. Appl.) 